\title{
Asian Guidelines on Hypertension
}

\author{
Jeong Bae Park \\ Cardiovascular Division, Department of Medicine, Cheil General Hospital, Kwandong \\ University College of Medicine, Seoul, South Korea
}

The prevalence of hypertension in most Asian countries has been increasing in the last 30 years and more dramatically in the last 10 years. Various factors are thought to have contributed to such drastic changes in Asia, but social and lifestyle changes due to rapid urbanization can be considered major contributing factors. Given that Asian countries comprise a large portion of the world's population, these changes will be a big burden on healthcare systems in Asia and around the world.

As expected, the characteristics of Asians and Asian hypertension are different from those of Eastern and other South and Western Asian countries. First, Asian countries are experiencing rapid aging of their societies, particularly in Far Eastern Asia. Second, the prevalence of diseases that constitute what we call a 'metabolic pandemic', for example, hypertension, obesity, poor lipid profile etc., is increasing due to the adoption of Western lifestyles. Third, despite various efforts made by the governments, salt intake levels are still high. Fourth, Asian countries have a relatively higher risk of stroke than Western countries even though the overall risk of coronary artery disease is lower. In addition, the relationship between blood pressure level and stroke incidence is stronger in Asia.

We now have evidence-based, highly qualified guidelines for hypertension management from Europe [1] and North America [2]. However, different characteristics of Asian hypertension necessitate the need for hypertension guidelines for Asian populations. In Asia, hypertension guidelines have recently been released from the Korean Society of Hypertension in 2013 [3], the Japanese Society of Hypertension in 2014 [4], and from the Taiwan Society of Cardiology and the Taiwan Hypertension Society in 2015 [5]. Also, hypertension guidelines from China [6] are expected to be updated this year.

This summarizes the essentials and key elements of the guidelines for hypertension management from China, Japan, Korea and Taiwan, focusing on the similarities and differences from the guidelines from Europe and North America. These efforts will hopefully serve as the groundwork for the concrete establishment of Asian hypertension guidelines. 
Park: Asian Guidelines on Hypertension

\section{References}

1 Mancia G, Fagard R, Narkiewicz K, et al: 2013 ESH/ESC Guidelines for the management of arterial hypertension: the Task Force for the management of arterial hypertension of the European Society of Hypertension (ESH) and of the European Society of Cardiology (ESC). Eur Heart J 2013;34:2159-2219.

-2 James PA, Oparil S, Carter BL, Cushman WC, Dennison-Himmelfarb C, Handler J, Lackland DT, LeFevre ML, MacKenzie TD, Ogedegbe O, Smith SC Jr, Svetkey LP, Taler SJ, Townsend RR, Wright JT Jr, Narva AS, Ortiz E: 2014 evidence-based guideline for the management of high blood pressure in adults: report from the panel members appointed to the Eighth Joint National Committee (JNC 8). JAMA 2014;311:507-520.

-3 Shin J, Park JB, Kim K, Kim JH, Yang DH, Pyun WB, Kim YG, Kim G-H, Chae SC; the Guideline Committee of the Korean Society of Hypertension: 2013 Korean Society of Hypertension guidelines for the management of hypertension. Part I - epidemiology and diagnosis of hypertension. Clin Hypertens 2015, in press.

-4 Shimada K, Shimosawa T, Suzuki H, Tamura K, Tanahashi N, Tsuchihashi T, Uchiyama M, Ueda S, Umemura S; Japanese Society of Hypertension Committee for Guidelines for the Management of Hypertension: The Japanese Society of Hypertension Guidelines for the Management of Hypertension (JSH 2014). Hypertens Res 2014;37:253-387.

-5 Chiang CE, Wang TD, Ueng KC, Lin TH, Yeh HI, Chen CY, Wu YJ, Tsai WC, Chao TH, Chen CH, Chu PH, Chao CL, Liu PY, Sung SH, Cheng HM, Wang KL, Li YH, Chiang FT, Chen JH, Chen WJ, Yeh SJ, Lin SJ: 2015 guidelines of the Taiwan Society of Cardiology and the Taiwan Hypertension Society for the management of hypertension. J Chin Med Assoc 2015;78:1-47.

6 Liu LS; Writing Group of 2010 Chinese Guidelines for the Management of Hypertension: 2010 Chinese guidelines for the management of hypertension (in Chinese). Zhonghua Xin Xue Guan Bing Za Zhi 2011;39: 579-615. 